\title{
Towards the Use of Software Modelling for Determination of Heavy Metal Speciation in Soils in Zambia
}

\author{
Kalebaila K. Kennedy*, Kamwela M. Zawadi \\ Department of Chemistry, School of Mathematics and Natural Sciences, Copperbelt University, Kitwe, Zambia \\ Email: *kkalebai@gmail.com
}

How to cite this paper: Kennedy, K.K. and Zawadi, K.M. (2018) Towards the Use of Software Modelling for Determination of Heavy Metal Speciation in Soils in Zambia. Open Access Library Journal, 5: e4706. https://doi.org/10.4236/oalib.1104706

Received: June 2, 2018

Accepted: July 23, 2018

Published: July 26, 2018

Copyright $\odot 2018$ by authors and Open Access Library Inc.

This work is licensed under the Creative Commons Attribution International License (CC BY 4.0).

http://creativecommons.org/licenses/by/4.0/

\begin{abstract}
The toxicity of heavy metals in water is typically related to the concentration of the metals in water. However, it is known that apart from the concentration the speciation of the heavy metals is also a critical factor. In this study, the concentration and type of species (ionic form) of $\mathrm{Cu}, \mathrm{Co}$, and $\mathrm{Pb}$ from two different soil samples on the Copperbelt Province in Zambia were investigated by modeling using Visual MINTEQ software. The concentration and the conductivity of the sample from ore-dump site were higher than that of the second site further away owing to the higher mineral content in the waste ore-dump site. Modeling by Visual MINTEQ uses defined parameters such as concentration, ionic conductivity and $\mathrm{pH}$ of the sample solutions to analyze the free metal ion and bound-metal distribution as a function of $\mathrm{pH}$. The results of the model showed that $\mathrm{Cu}^{2+}, \mathrm{Pb}^{2+}$ and $\mathrm{Co}^{2+}$ ions thrive in aqueous acidic solutions up to $\mathrm{pH}$ 6.5. At higher $\mathrm{pH}$, formation of the hydroxo and bicarbonate species leads to a decline in the concentration of the divalent ions. Interestingly, the $\mathrm{Co}^{2+}$ ion persists in solution up to $\mathrm{pH} 8.5$ with little formation of the hydroxo or carbonate forms. Finally, the results show that without elaborate analytical tools, speciation modeling can be used to ascertain the availability of metal ions in soils/aqueous solutions when chelating and competing metal ions are taken in consideration.
\end{abstract}

\section{Subject Areas}

Environmental Chemistry

\section{Keywords}

Visual MINTEQ, Speciation, Ionic Conductivity, Heavy Metals, Toxicity 


\section{Introduction}

Zambia contains the largest known reserves of copper in Africa and is among the top countries that have continued to dominant the world copper mining industry. With so much mining activities on the Copperbelt Province, there is so much risk of environmental damage from heavy metal discharges in water bodies as reported by Centre for Trade Policy and Development [1]. The Copperbelt Province is characterized by tailings and slag dumps from mining and refining of ores which pose a great source of potentially toxic heavy metals in water and soil. Cobalt and lead are byproducts of the refining of other mined metals such as copper and nickel.

Heavy metals are more accurately referred to metals and metalloids that are stable and have density greater than $5 \mathrm{~g} / \mathrm{cm}^{3}$ such as $\mathrm{Cu}, \mathrm{Co}, \mathrm{Zn}, \mathrm{Ni}$ and $\mathrm{Pb}$ as discussed by Duffus [2]. Robert et al. [3] have reported that the different forms i.e. chemical, physical and biological, determines the distribution and fate of heavy metals in the eco-system. Metal ions can form insoluble and soluble complexes at different $\mathrm{pH}$ and this in turn determines whether they will be up-taken by plants or not.

The toxicity of heavy metals is known not only to depend on the concentration, but the also the physicochemical forms in which metals appear in soil. The different molecular forms of metals interact with different chemical components of the soil and are redistributed differently in the environment. This relationship determines the mobility, bioavailability, and the toxicity that heavy metals impart on the ecosystem as described by $\mathrm{Ge}$ [4].

Metal speciation is the process of identifying and quantifying different species of metals and their forms of occurrence in an environmental sample. Most of the properties of metals like solubility, adsorption-desorption processes, complex formation and dissolved and exchangeable forms (bioavailable) are affected by soil $\mathrm{pH}$. Although, quantifying the total metal concentration is easier, the results are known to unreliable since non-bioavailable metal forms are not accounted for when determining the total metal concentration. Shahid et al. [5] emphasized that the determination of metal speciation had formed a major part in assessing the behavior of the metals in the environment.

Although, having knowledge of the full speciation of a substance to ascertain its activities in the ecosystem, it is usually not possible to determine speciation using analytical techniques alone as suggested by VanBriesen et al. [6] Experimental methods such as single and sequential extraction techniques, ion-selective electrode and anodic stripping voltammetry offer a more analytical approach to characterizing the various fractions into which metal cations can exist or be bound. As discussed elsewhere [7] [8] [9] the analytical methods lack the ease and simplicity that computer programs offer.

\section{Metal Speciation Modeling}

Computer programs have been developed in achieving elemental speciation, distribution, ion activity and toxicology in various aqueous media. These pro- 
vide an alternative approach to metal speciation in the absence of or inadequate analytical methods. Some of the examples of computer programs for metal speciation modeling include WHAM, PHREEQ and Visual MINTEQ. These programs can accurately predict metal speciation and thus provide important and quick information about the behavior and fate of a metal in a medium. As reported in [5] [10] [11] the models use the metal binding ability of ligands and soil components to calculate metal speciation.

Gustafsson [12] developed Visual MINTEQ is a freeware chemical equilibrium model that can be used to calculate metal speciation, solubility equilibrium, sorption and toxicology, of metals in aqueous sources. The program applies known thermodynamic relationships among the chemical forms to predict equilibrium distribution. In this work, Visual MINTEQ was used to estimate metal speciation of field samples collected from mining area on the Copperbelt. The metal speciation (soluble or insoluble) was determined by finding the total metal concentration, the $\mathrm{pH}$ and the ionic strength of the soil solution samples. For this wok, cobalt, copper, and lead were chosen because the mining activities on the Copperbelt constantly produce these heavy metals as waste.

\section{Materials and Methods}

\subsection{Sampling Site and Sample Pre-Treatment}

Two heavy metal polluted soil samples were collected from the Copperbelt Province, Zambia influenced by mining activities. The first sampling site was located in Nkana West close to a waste ore-site (Site 1). The second area (Site 2) was located $500 \mathrm{~m}$ away from the ore-waste site. For each site $500 \mathrm{~g}$ of soil samples were taken within a triangular radius at a depth of $20 \mathrm{~cm}$. Samples were air dried at room temperature and further at $85^{\circ} \mathrm{C}$ to a constant weight. About $250 \mathrm{~g}$ of representative samples were pulverized and passed through a sieve mesh of $2 \mathrm{~mm}$.

\subsection{Extraction and Analysis of Heavy Metals}

Determination of heavy metal content in the soil samples was done using the wet acid digestion method. About $2 \mathrm{~g}$ of the soil sample was digested in $50 \mathrm{~mL}(3: 1)$ $\mathrm{HCl}: \mathrm{HNO}_{3}$ mixture at $130^{\circ} \mathrm{C}$ to a final volume of $10 \mathrm{~mL}$. After cooling, $5 \mathrm{~mL}$ $\mathrm{HClO}_{4}$ was added and the sample reheated for 10 minutes, then $50 \mathrm{~mL}$ of deionized water and $25 \mathrm{~mL} \mathrm{HCl}$ acid were added and left until boiling. After cooling the sample was transferred to a $250 \mathrm{~mL}$ Erlenmeyer flask and diluted with distilled water to the mark. This was repeated for all the two soil samples. Table 1 shows the metal ion concentration of each metal species $(\mathrm{Cu}, \mathrm{Co}$, and $\mathrm{Pb})$ in the soil samples analyzed by Atomic Absorption Spectroscopy (AAS) on a Perkin Elmer analyzer, along with WHO allowable limits.

\subsection{Soil pH, Conductivity Measurements and Calculation of Ionic Strength}

About $10 \mathrm{~g}$ of air-dried soil sample was dispersed in $0.01 \mathrm{M} \mathrm{CaCl}_{2}$ solution and allowed to settle for 1 hour. The $\mathrm{pH}$ of the soil samples were determined by au- 
tomated Multi 3320 meter calibrated with two buffer solutions at $\mathrm{pH} 4.0$ and $\mathrm{pH}$ 7.0. Table 2 indicates the conductance readings recorded on the digital meter Multi 3320 meter using $0.01 \mathrm{M} \mathrm{KCl}$ as a reference solution. The ionic strength, $I_{s}$, is estimated from the measurements of conductivities of the soil solutions and calculated by using Equation (1):

$$
I_{s}=1.7 \times 10^{-5} \times \operatorname{SpC}\left(\mu \mathrm{S} \cdot \mathrm{cm}^{-1}\right)
$$

where $S p C$ is the specific conductance in micro Siemens per centimeter. The values obtained from this estimation are used as input for the model.

\subsection{Visual MINTEQ Model}

Laboratory results for $\mathrm{pH}$, metal concentration and ionic strength values at field capacity are the input data for Visual MINTEQ to calculate metal speciation. For a specific metal, chemical speciation diagrams of the logarithm of activity as a function of $\mathrm{pH}$ were computed to determine the dominant metal species for a $\mathrm{pH}$ range of 4.5 to 8 . All experiments were carried out in an open system; as a result, the partial pressure of carbon dioxide was specified and assumed at $3.8 \times$ $10^{-4}$ atmospheres. The software contains different equations for analysis of metal species for different conductivities. In this work, the Davies equation was used for activity correction, since the ionic strengths of these soil solutions lay within the interval of $10^{-5}$ to $10^{-2.3}$. The validity of the Davies equation is limited to low-to-intermediate ionic strengths i.e. $\mathrm{I}<0.3 \mathrm{M}$.

Visual MINTEQ takes raw concentration data, $\mathrm{pH}$, and other input parameters and converts them into activities by using the Davies Equation. The Davies Equation performs repeated computational analysis over the aqueous complexation constants and mass and charge balance expressions. The results from the model predict which species are thermodynamically favored to precipitate or dissolve in aqueous solutions and at what $\mathrm{pH}$. In addition, Visual MINTEQ searches its database for all the possible metal species that can form and calculates the activity

Table 1. Total concentrations of heavy metals at the two sampling yards.

\begin{tabular}{cccc}
\hline Heavy Metal & Site $1, \mathrm{mg} / \mathrm{kg}$ & Site $2, \mathrm{mg} / \mathrm{kg}$ & WHO, $\mathrm{mg} / \mathrm{kg}^{*}$ \\
\hline Copper & 638 & 415 & 100 \\
Cobalt & 518 & 473 & 50 \\
Lead & 36 & 26 & 100 \\
\hline
\end{tabular}

*Environment, European Commission on Environment. (2002). Heavy Metals in Wastes. http://ec.europa.eu/environment/waste/studies/pdf/heavy_metalsreport.pdf. Retrieved November 16, 2017.

Table 2. Conductivity and $\mathrm{pH}$ values at room temperature.

\begin{tabular}{cccc}
\hline Site & Conductivity, $\mu \mathrm{S} \cdot \mathrm{cm}^{-1}$ & Temperature, ${ }^{\circ} \mathrm{C}$ & $\mathrm{pH}$ \\
\hline 1 & 173 & 27 & 7.0 \\
2 & 149 & 27 & 7.0 \\
\hline
\end{tabular}


which is expresses as $\log$ activity or $\log \{\alpha\}$. The less negative $\log \{\alpha\}$, the more activity the metal species is able to bind to organic matter or exist as free cations.

\section{Results and Discussions}

Although two samples sets were collected the modeling, results presented here are from Site 1. The modeling results from the two sites were similar since the metal species present in each sample were the same.

\subsection{Concentration of Metal Ions from AAS}

The concentration of $\mathrm{Cu}, \mathrm{Co}$ and $\mathrm{Pb}$ obtained from first sampling site near the ore-waste sites were higher than those collected from the second site. The ore-waste site is expected to have higher metal concentration being the dump site. Further away from the dump site, the decrease in metal concentration in the soils along the stream is due to dilution where most of the metals get trapped in soils along the edges of the stream consistent with reports by Hudson-Edwards et al. [13]. As demonstrated in Table 1, the concentration of these metals is still much higher than the $\mathrm{WHO}$ allowable limits. In addition, the conductivity of the sample from ore-dump site was higher $\left(172 \mu \mathrm{S} \cdot \mathrm{cm}^{-1}\right)$ than that of site $2\left(148 \mu \mathrm{S} \cdot \mathrm{cm}^{-1}\right)$ owing to the higher mineral content in the waste ore-dump site. This implies that the unchecked discharge of heavy metals from mining industries on the Copperbelt in Zambia is still rampant despite studies to highlight this problem as reported by Volk and Yerokun [14].

\subsection{Metal Speciation and Activity as a Function of $\mathrm{pH}$}

\subsubsection{Copper}

The thermodynamic speciation calculated at $25^{\circ} \mathrm{C}$, as shown in Figure 1, suggests that free $\mathrm{Cu}^{2+}$ ions are the dominant species in aqueous phase up to a $\mathrm{pH}$ of 6.5. At $\mathrm{pH}$ value $>6.5$, formation of up to $80 \% \mathrm{CuCO}_{3}$ occurs until $\mathrm{pH} 8.5$, while at the same time the electropositive $\mathrm{CuOH}^{+}$complex was formed progressively up to $\mathrm{pH} 7.5$ (20\%). The results from this work parallel reports in the literature concerning solubility and speciation of copper. A recent study by Ibrahim [15] on the geochemical composition of $\mathrm{Cu}$ in fly ash extracts using Visual MINTEQ showed that as time increased the main inorganic species was $\mathrm{CuCO}_{3}(85.3 \%)$ of the total dissolved $\mathrm{Cu}$. It was further reported that the other species of $\mathrm{Cu}$ at higher $\mathrm{pH}$ were in the form of $\mathrm{CuOH}^{+}, \mathrm{Cu}\left(\mathrm{CO}_{3}\right)_{2}^{2-}, \mathrm{Cu}(\mathrm{OH})_{2}, \mathrm{Cu}_{2}(\mathrm{OH})_{2}^{2+}$ and $\mathrm{CuHCO}_{3}^{+}$. A study by Wang et al. [16] on the effects of $\mathrm{Cu}$ on barley plants suggested that the $\mathrm{pH}$-related toxicity of $\mathrm{Cu}$ was due changes of $\mathrm{Cu}$ species in solutions. Nigoyi and Wood [17] reported that apart from free $\mathrm{Cu}^{2+}$, species as such as $\mathrm{CuCO}_{3}$ and $\mathrm{CuOH}^{+}$were also toxic to organismsin a medium with relatively high $\mathrm{pH}$. Furthermore, Stumm and Morgan [18] reported that precipitation of malachite $\left[\mathrm{Cu}_{2}(\mathrm{OH})_{2} \mathrm{CO}_{3}\right]$ is significant in lowering the amount of free $\mathrm{Cu}^{2+}$ ion in aqueous media. Moreover, they indicated using analytical methods that $\mathrm{Cu}^{2+}$ is dominant in aqueous solution up to $\mathrm{pH} 6$ and from $\mathrm{pH} 6-9.3$, 
aqueous $\mathrm{CuCO}_{3}$ is common.

The literature results give credibility to the modeling methods of determining copper speciation in soil solutions as reported by Stumm and Morgan [18]. Figure 2 shows the log activity results for copper species considered shows that $\mathrm{Cu}^{2+}$ is the most active, $-\log 4$, to be bound on soils up to $\mathrm{pH}$ 6. Contrary, $\mathrm{Cu}$ $\mathrm{CO} 3$ that is prevalent at high $\mathrm{pH}$ shows negligible activity at $-\log 8$ and would not be expected to be bound to soils. In general, the activity of ions in a solution not only depends on whether the ionic strength is high or low, but also on the availability of the ions in solution as reported by Fennema [19].

\subsubsection{Cobalt}

In contrast to $\% \mathrm{Cu}$ species, Figure 3 reveals that free $\mathrm{Co}^{2+}$ persists in solutions over a wider range of $\mathrm{pH}$ from 4.5 - 8, with only insignificant amounts $\mathrm{CoOH}^{+}$ and $\mathrm{CoHCO}_{3}^{+}$forming in highly basic soil solutions. Researchers have reported that uptake of Co from soil by plants to parts above the roots is generally not prominent except in very acidic soils $\sim \mathrm{pH} 3.3$. Further reports indicate that cobalt is easily taken up by organic matter forming chelates that increases the mobility of cobalt. Other researchers [20] [21] have reported that the mobility and uptake is greater in soils of very low $\mathrm{pH}$, although even at high $\mathrm{pH}$ cobalt is also more readily soluble, and thus available for plants. Figure 4 shows that the divalent cobalt is mainly responsible for the activity of the metal, even though the $\mathrm{CoOH}^{+}$and $\mathrm{CoHCO}_{3}^{+}$forms are present in solution. In their study of cobalt speciation in methanogenic sludge, Bartacek et al. [22] reported that the toxicity of cobalt was not only based on the total cobalt concentration, but also on the quantity of the metal precipitated. They concluded that cobalt toxicity could be assessed from the free cobalt concentration when $\mathrm{pH}$ and the concentration of competing metals are kept constant.

From the modeling results in this work, as the $\mathrm{pH}$ increases beyond 8 , formation of insoluble hydroxides or carbonates is highly possible and this would reduce the cobalt availability/mobility from soils.

\subsubsection{Lead}

The behavior $\mathrm{Pb}$ species in aqueous solutions as indicated in Figure 5 was very similar to that of copper. The divalent $\mathrm{Pb}^{2+}$ ions are more prevalent up to $\mathrm{pH} \leq$ 6.5 , the decrease in $\mathrm{Pb}^{2+}$ species is accompanied by accumulation of $\mathrm{PbOH}^{+}$ complex that formed progressively up to $\mathrm{pH}$ 7.5. The results are consistent with those modeled by Shahid [5] where the distribution of different forms of $\mathrm{Pb}$ in nutrient solution showed that free $\mathrm{Pb}^{2+}$ was the most abundant species $(80 \%$ $90 \%)$ under acidic conditions and the $\mathrm{Pb}-\mathrm{OH}$ species $(90 \%-100 \%)$ under alkaline condition. Contrary, Ibrahim [15] suggested that although free $\mathrm{Pb}^{2+} \mathrm{ac}^{-}$ counted for only 3.5\%, while the dominant species was $\mathrm{PbCO}_{3}$ (80.3\%) which accounted for of total dissolved lead and controls $\mathrm{Pb}^{2+}$ activities. Gustafsson [23] emphasizes that $\mathrm{Pb}^{2+}$ forms a range of stable compounds with oxo-ligands like $\mathrm{OH}$ and $\mathrm{COO}^{-}$on organic matter, thus despite having $\mathrm{Pb}^{2+}$ in solution, the mobility of divalent ion will be hindered by complexation with organic matter. 
The activity of for lead species depicted in Figure 6 is lower than those of cobalt and copper species, even though the divalent $\mathrm{Pb}$ form is still more active than the $\mathrm{PbOH}^{+}$and the $\mathrm{PbHCO}_{3}^{+}$forms. As was the case with copper, the decrease in activity of the overall $\mathrm{Pb}^{2+}$ aqueous species, was due to formation of $\mathrm{PbOH}^{+}$and the $\mathrm{PbHCO}_{3}$ at high pH. Kabata-Pendias and Pendias [24] reported that the most the risk of lead poisoning is not by the uptake of $\mathrm{Pb}$ by plants, but by contact with contaminated soils and inhalation of lead dust deposits.

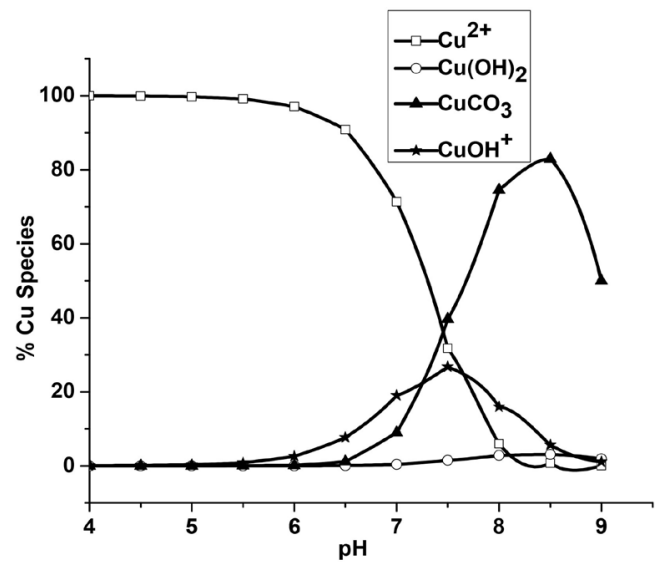

Figure 1. Equilibrated mass distribution of copper species as a function of $\mathrm{pH}$.

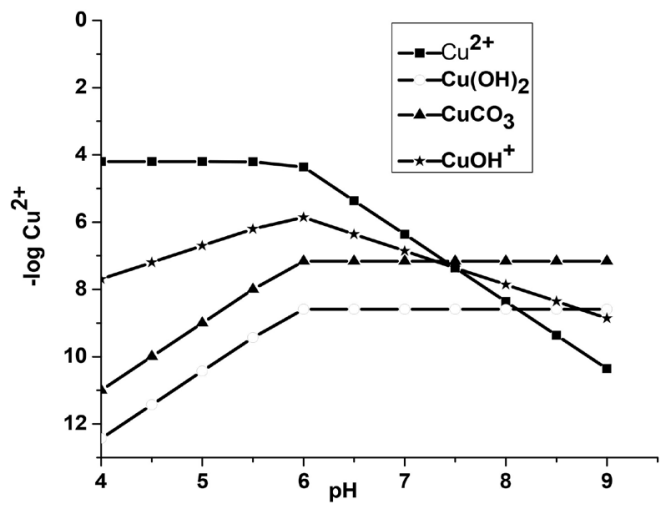

Figure 2. Activity of common copper species as a function of solution $\mathrm{pH}$.

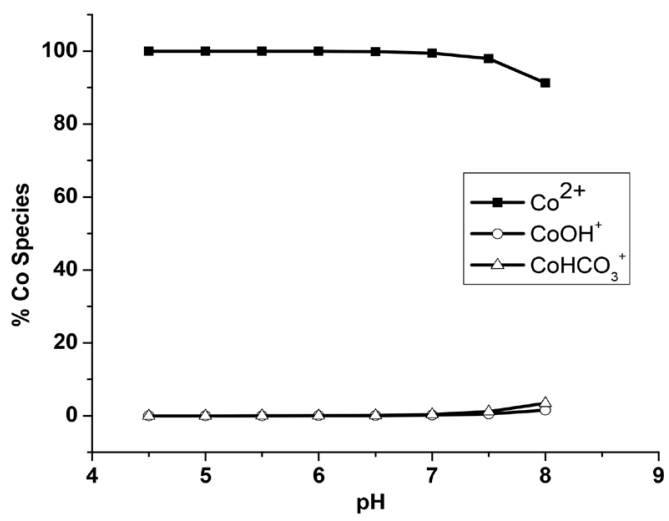

Figure 3. Equilibrated mass distribution of Co species as a function of $\mathrm{pH}$. 


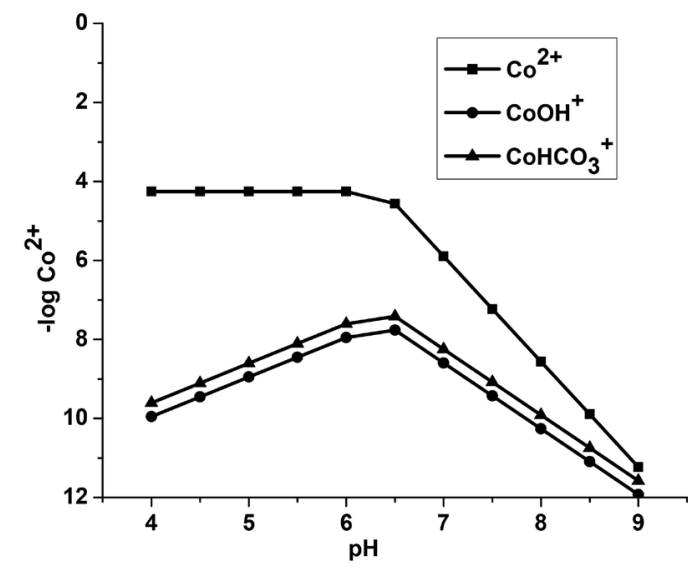

Figure 4. Activity of common cobalt species as a function of solution $\mathrm{pH}$.

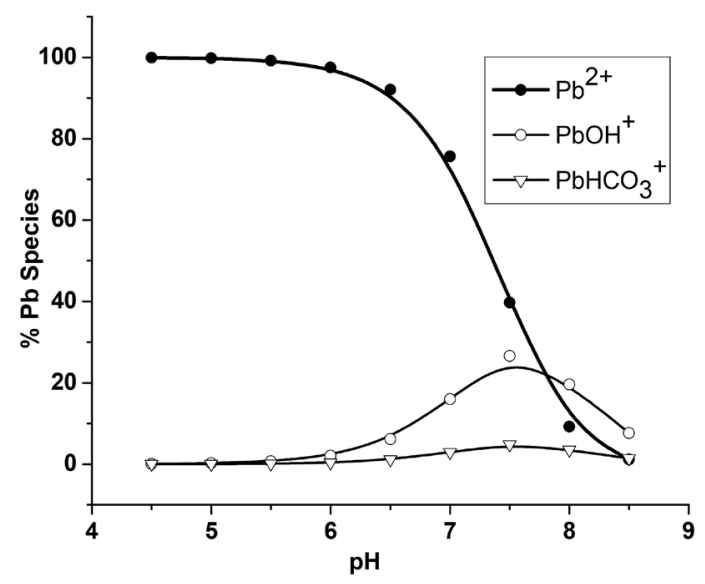

Figure 5. Equilibrated mass distribution of Pbspecies as a function of $\mathrm{pH}$.

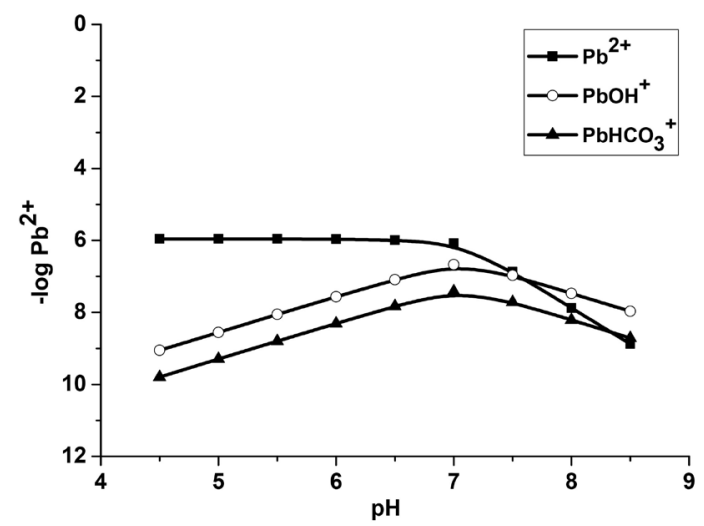

Figure 6. Activity of common cobalt species as a function of solution $\mathrm{pH}$.

\section{Conclusions}

The results of the study were two-fold. First the results confirms that the problem of high levels of $\mathrm{Cu}$ and $\mathrm{Co}$ in Zambia has not being mitigated by the mining industries despite several studies indicating very high concentrations of the metals. Secondly, despite having high metal concentrations, the most important 
concern is determining how much of these metals are bioavailable as much of them will be insoluble at different $\mathrm{pH}$ values. The results show that $\mathrm{Cu}^{2+}, \mathrm{Pb}^{2+}$ and $\mathrm{Co}^{2+}$ ions thrive in aqueous acidic solutions, and each metal ion forms different species. Hydrolysis products, including $\mathrm{Pb}(\mathrm{OH})_{3}^{-}$, and $\mathrm{Cu}(\mathrm{OH})_{2}$ thrive in weakly acidic to alkaline solutions. It can be concluded that, under natural conditions (i.e. $\mathrm{pH}$ of surface water and of 6 to 8.5), $\mathrm{Cu}$ and $\mathrm{Pb}$ will probably exist as slightly soluble carbonate or hydroxides and not are effectively available for uptake by plants. However, repeated accumulation in humans via the food chain will lead to an increase in the amounts of the minerals in the body.

Finally, the computer modeling results offer information about the state of a metal under whether it will be available for up-take by plants or not. The implementation of the model would be recommended as part of routine soil and indeed water analysis to ascertain what form of the metal is readily available. Future studies, using the model would include addition of different organic matter to the soil solutions at different $\mathrm{pH}$ values to ascertain the binding ability of the metal ions.

\section{Acknowledgements}

The authors would like to thank the staff in Chemical Engineering at the Copperbelt University for the AAS and conductivity measurements and the Copperbelt University Student Research Funding to make this study possible.

\section{Conflicts of Interest}

The authors declare no conflicts of interest regarding the publication of this paper.

\section{References}

[1] Centre for Trade Policy and Development (2012) Pollution in Copperbelt Province of Zambia: A Case Study of Kankoya. Counter Balance Report, Mufulira.

[2] Duffus, J.H. (2002) Heavy Metals-A Meaningless Term? IUPAC Technical Report, 74, 793-807.

[3] Roberts, D., Sparks, D.L. and Maarten, N. (2002) Speciation of Metals in Soils. In: Robets, D., Sparks, D.L. and Maarten, N., Eds., Chemical Processes in Soils, Soil Science Society of America, 622-623.

[4] Ge, Y. (1999) Trace Metal Speciation and Bioavailability in Urban Contaminated Soils. National Library of Canada, Ottawa.

[5] Shahid, M., Dumat, C., Aslam, M. and Pinelli, E. (2012) Assessment of Lead Speciation by Organic Ligands. Chemical Speciation \& Bioavailability, 24, 248-252. https://doi.org/10.3184/095422912X13495331697627

[6] VanBriesen, J.M., Small, M., Weber, C. and Wilson, J. (2010) Modelling Chemical Speciation: Thermodynamics, Kinetics and Uncertainty. In: Hanrahan, G., Ed., Modelling of Pollutants in Complex Environmental Systems, ILM Publications, Hertfordshire, 35-148.

[7] Tessier, A., Campbell, P.G.C. and Bisson, M. (1979) Sequential Extraction Procedure for the Speciation of Particulate Trace Metals. Analytical Chemistry, 51, 
844-851. https://doi.org/10.1021/ac50043a017

[8] Roa, G., Ramirez-Silva, M., Romero-Romo, M. and Galicia, L. (2003) Determinarion of Lead and Cadmium Using a Polycyclodextrin-Modified Carbon Paste Electrode with Anodic Stripping Voltammetry. Analytical and Bioanalytical Chemistry, 377, 763-769. https://doi.org/10.1007/s00216-003-2126-4

[9] Wardak, C. and Lenik, J. (2013) Ion-Selective Electrodes with Solid Contact for Heavy Metals Determination. E3S Web of Conferences, 1-3. https://doi.org/10.1051/e3sconf/20130105009

[10] Bisan, E. and Luca, C. (2010) Speciation of Heavy Metals in Surface Waters Polluted by Athropogenic Activities. Scientific Study and Research: Chemistry and Chemical Engineering, 11, 439-448.

[11] Unsworth, E.R., Warnken, K.W., Zhang, H., Davison, W., Black, F., Buffle, J., Cao, J., Cleven, R., Galceran, J., Gunkel, P., Kalis, E., Kistler, D., van Leeuwen, H.P., Martin, M., Noël, S. and Nur, Y. (2006) Model Predictions of Metal Speciation in Freshwaters Compared to Measurements by in Situ Techniques. Environmental Science Technology, 40, 1942-1949. https://doi.org/10.1021/es051246c

[12] Gustafsson, J. (2000) Visual MINTEQ Ver. 3.1. https://vminteq.lwr.kth.se/

[13] Hudson-Edwards, K.A., Macklin, M.G., Miller, J.R. and Lechler, P.J. (2001) Sources, Distribution and Storage of Heavy Metals in the Río Pilcomayo, Bolivia. Journal of Geochemical Exploration, 72, 229-250. https://doi.org/10.1016/S0375-6742(01)00164-9

[14] Volk, J. and Yerokun, O. (2016) Effect of Application of Increasing Concentrations of Contaminated Water on the Different Fractions of $\mathrm{Cu}$ and Co in Sandy Loam and Clay Loam Soils. Agriculture, 6, 64-83. https://doi.org/10.3390/agriculture6040064

[15] Ibrahim, I.A.A. (2015) Chemical Characterization and Mobility of Metal Species in Fly Ash-Water System. Water Science, 29, 109-122.

https://doi.org/10.1016/j.wsj.2015.10.001

[16] Wang, X., Hua, L. and Ma, Y. (2012) A Biotic Ligand Model Predicting Acute Copper Toxicity for Barley (Vulgare): Influence of Calcium, Magnesium, Sodium, Potassium and $\mathrm{pH}$. Chemosphere, 89, 89-95. https://doi.org/10.1016/j.chemosphere.2012.04.022

[17] Niyogi, S. and Wood, C. (2004) Biotic Ligand Model, a Flexible Tool for Developing Site-Specific Water Quality Guidelines for Metals. Environmental Science and Technology, 38, 6177-6192. https://doi.org/10.1021/es0496524

[18] Stumm, W. and Morgan, J. (1996) Aquatic Chemistry. 3rd Edition, Wiley Interscience, New York.

[19] Fennema, O. (1996) Food Chemistry. 3rd Edition, Macel Dekker Inc., New York.

[20] Baralkiewicz, D. and Siepak, J. (1999) Chromium, Nickel and Cobalt in Environmental Samples and Existing Legal Norms. Polish Journal of Environmental Studies, 8, 201-208.

[21] Boikat, U., Andrea, F. and Bleck-Neuhaus, J. (1985) Cesium and Cobalt Transfer from Soil to Vegetation on Permanent Pastures. Radiation and Environmental Biophysics, 24, 287-301. https://doi.org/10.1007/BF01210936

[22] Bartacek, J., Fermoso, F., Baldó-Urrutia, A., van Hullebusch, E. and Lens, P. (2008) Cobalt Toxicity in Anaerobic Granular Sludge: Influence of Chemical Speciation. Journal of Industrial Microbiology and Biotechnology, 35, 1465-1474.

https://doi.org/10.1007/s10295-008-0448-0 
[23] Gustafsson, J. (2011) Modelling Lead (II) Sorption to Ferrihydrite and Soil Organic Matter. Environmental Chemistry, 8, 485-492. https://doi.org/10.1071/EN11025

[24] Kabata-Pendias, A. and Pendias, H. (2001) Trace Metals in Soils and Plants. 2nd Edition, CRC Press, Boca Raton. 